\title{
ARMAZENAMENTO DE SEMENTES DE CATANDUVA (Piptadenia moniliformis Benth.) EM DIFERENTES AMBIENTES E EMBALAGENS ${ }^{1}$
}

\author{
CLARISSE PEREIRA BENEDITO², MARIA CLARETE CARDOSO RIBEIRO ${ }^{3}$, \\ SALVADOR BARROS TORRES ${ }^{4}$, RAMIRO GUSTAVO VALELA CAMACHO ${ }^{5}$, ADRIELLE NAIANA RIBEIRO SOARES ${ }^{6}$, \\ LOUISE MEDEIROS SILVA GUIMARÃES?
}

\begin{abstract}
RESUMO - Neste trabalho objetivou-se avaliar a viabilidade das sementes de Catanduva (Piptadenia moniliformis Benth.) armazenadas por 210 dias, em ambiente controlado e condição ambiental não controlada (sala de laboratório), acondicionadas em saco plástico, saco de papel e frasco de vidro. O delineamento experimental foi inteiramente casualizado, em esquema de parcela sub-subdividida, com os ambientes alocados na parcela principal, as embalagens nas subparcelas, sendo as sub-subparcelas constituídas dos tempos de armazenamento (0, 30, 60, 90, 120, 150, 180 e 210 dias). Os ensaios foram realizados em laboratório e em casa de vegetação. Em laboratório foram avaliados, a cada 30 dias, a porcentagem de germinação e o índice de velocidade de germinação. Em casa de vegetação, a cada 30 dias, foi avaliada a emergência de plântulas. A germinação das sementes e a emergência das plântulas de catanduva decresceram em função do tempo de armazenamento durante 210 dias. As sementes de catanduva podem ser acondicionadas tanto em embalagem de vidro quanto em sacos plásticos sem perda do seu potencial fisiológico por 210 dias, sendo o ambiente controlado (18-20 ${ }^{\circ} \mathrm{C}, \pm 60 \%$ UR) o mais adequado.
\end{abstract}

Termos para indexação: Piptadenia moniliformis, armazenamento, viabilidade.

\section{STORAGE OF CATANDUVA SEED (Piptadenia moniliformis Benth.) IN DIFFERENT ENVIRONMENTS AND PACKAGING}

\begin{abstract}
This study aimed to evaluate the viability of catanduva seeds stored for 210 days under controlled and uncontrolled environmental conditions (laboratory), in plastic, paper and glass packaging. The experimental design was completely randomized in a sub-subdivided plot, where the main plot were the storage conditions (laboratory and cold room) and sub-plots consisted of the packaging (plastic and paper bags and glass bottles) and sub-sub-plots of the storage times
\end{abstract}

${ }^{1}$ Submetido em 06/02/2010 . Aceito para publicação em 27/08/2010. Parte da dissertação de mestrado da primeira autora.

${ }^{2}$ Engenheira agrônoma, doutoranda em Agronomia/ Fitotecnia (UFERSA), bolsista de doutorando da CAPES, e-mail: clarissepb@yahoo.com.br

${ }^{3}$ Dra, Professora Associada, Departamento de Ciências Vegetais (UFERSA), C.P. 137, CEP 59625-900, Mossoró, RN, e-mail: clarete@ufersa.edu.br

${ }^{4}$ EMPARN/UFERSA, Departamento de Ciências Vegetais, C.P. 137, CEP
59625-900, Mossoró, RN, e-mail: sbtorres@ufersa.edu.br

${ }^{5}$ Universidade ro Rio Grande do Norte (UERN), CEP: 59633-010, Mossoró, RN. E-mail: ramirogustavo@uern.br

${ }^{6}$ Engenheiro agrônomo, bolsista da Empresa de Assistência Técnica e Extensão Rural (EMATER-RN), E-mail: adrielle.naiana@hotmail.com.

${ }^{7}$ Bioquímica, Técnica em Laboratório, Departamento de Ciência Vegetais (UFERSA), E-mail: louise@ufersa.edu.br 
$(0,30,60,90,120,150,180$ and 210 days). The tests were conducted in the laboratory and greenhouse. Evaluations were made every 30 days of the percentage of germination and the rate of germination velocity in the laboratory and of seedling emergence in the greenhouse. The seed viability of catanduva decreased as a function of storage time during the 210 days. Catanduva seeds (Piptadenia moniliformis Benth.) can be packed for 210 days either in glass bottles or plastic bags without losing their physiological potential. The controlled environment $\left(18-20^{\circ} \mathrm{C}\right.$, $\pm 60 \% \mathrm{RH})$ is the most suitable.

Index terms: Piptadenia moniliformis, storage, viability.

\section{INTRODUÇÃO}

Dentre as espécies nativas do Nordeste brasileiro, a Piptadenia moniliformis Benth. é conhecida pelos nomes populares de catanduva, catanduba, rama-de-bezerro (PI), muquem, angico-de-bezerro, surucucu (BA), quipembé (PE) e carrasco (PA) (Lorenzi, 2002; Azêredo, 2009). Porém, na maioria das regiões do Nordeste é mais conhecida como catanduva. É uma espécie arbórea, sem espinhos que pode atingir de 4 a 9 metros de altura, pertencente à família Fabaceae e subfamília Mimosoideae. Sua madeira é pesada, de textura média, grã-reversa, de média resistência mecânica e boa durabilidade natural. É empregada apenas localmente em pequenas obras de construção civil, marcenaria leve, cabo de ferramentas e para lenha e carvão. É uma espécie rústica e de rápido crescimento, portanto, indicada para composição de reflorestamentos heterogêneos para fins preservacionistas. É encontrada desde o Maranhão, Piauí e Ceará até a Bahia, na Caatinga, sendo particularmente frequente no Vale do Rio São Francisco. Planta decídua, heliófita, pioneira, característica e exclusiva das caatingas do Nordeste brasileiro, onde é muito abundante e com dispersão mais ou menos continua e irregular (Lorenzi, 2002).

Mesmo com o aumento do incremento nas pesquisas, o conhecimento atual sobre as espécies arbóreas nativas ainda são escassos para assegurar o sucesso de repovoamentos, o que se deve ao desconhecimento das exigências ecofisiológicas para o seu estabelecimento e perpetuação (Rêgo e Possamai, 2003). Por outro lado, em função do fortalecimento da política ambiental ocorreu aumento da demanda por sementes de espécies nativas, que constituem insumo básico nos programas de recuperação e conservação de ecossistemas (Carvalho et al., 2006). Com essa demanda técnica, motivou-se a realização de pesquisas com sementes de espécies arbóreas (Santos e Aguiar, 2000).

Normalmente, as sementes não são utilizadas imediatamente após a coleta. Por isso, devem ser armazenadas para utilização futura no mesmo ano ou até nos anos seguintes, pois nas espécies nativas a produção de sementes é cíclica, caracterizadas por um ano de alta produção, seguido de um ou dois de baixa produção. Em decorrência disso, existe a necessidade de manter a viabilidade das sementes durante o armazenamento, minimizando a velocidade de deterioração, por meio de tecnologias de conservação apropriadas para cada espécie (Kissmann, 2009). Além disso, a utilização de sementes de baixa qualidade é um dos fatores responsáveis pela obtenção de mudas de espécies florestais de baixa qualidade, com reflexos negativos no estabelecimento e na uniformidade de povoamentos, sendo necessário o armazenamento em local e condições que permitam sua conservação com o mínimo de deterioração (Corvello et al., 1999).

A classificação fisiológica das sementes de espécies florestais nativas do Brasil quanto à capacidade de armazenamento permite que sejam adotadas condições de armazenamento adequadas para cada espécie, além da elaboração de programas para a conservação de germoplasma. No entanto, diante da grande diversidade de espécies nas florestas tropicais, a literatura ainda é deficiente sobre a tecnologia a ser adotada (Davide et al., 2003).

Existem estratégias básicas de conservação in situ e ex situ. A primeira refere-se à manutenção das espécies selecionadas no seu habitat, em parques, reservas biológicas ou reservas ecológicas; enquanto a conservação ex situ se refere à manutenção de espécies vegetais fora do seu ambiente natural através de coleções de plantas 
no campo, em bancos de sementes, ou de coleções de plântulas em bancos in vitro (Santos, 2000).

O processo de deterioração é a soma de todas as alterações físicas, fisiológicas, químicas e bioquímicas que ocorrem nas sementes, conduzindo-as à perda total de viabilidade (Fowler, 2000). A rapidez de deterioração das sementes de algumas espécies nativas e o período em que a viabilidade pode ser mantida varia de algumas semanas a poucos meses, por isso as pesquisas sobre armazenamento de sementes de espécies florestais assumem caráter de extrema importância (Carneiro e Aguiar, 1993). A deterioração não pode ser evitada, mas pode ser controlada, através do armazenamento adequando, que está entre as estratégias de conservação ex situ mais utilizadas, por preservar as características genéticas das sementes até que sejam semeadas (Nodari et al., 1998).

Deste modo, o armazenamento das sementes tem como objetivos principais a formação de plantios comerciais e também de bancos de genes de florestas nativas o que determina a necessidade de conservação por períodos curtos ou longos. Além disso, o armazenamento de sementes nativas tem a função de manter uma disponibilidade contínua de sementes viáveis, imprescindíveis aos programas florestais, como os reflorestamentos, recuperação de áreas degradadas e programas de melhoramento, além de conservação de germoplasma por longos períodos, principalmente para as espécies ameaçadas de extinção (Floriano, 2004). O comportamento das sementes durante o armazenamento é função dos fatores que afetam sua conservação, tais como a temperatura, umidade relativa do ar, grau de umidade das sementes e tipo de embalagem utilizada (Carneiro e Aguiar, 1993).

Alguns trabalhos têm mostrado que algumas sementes acondicionadas em embalagem impermeável podem ser armazenadas em ambiente não controlado (Carneiro e Aguiar, 1993). Para o armazenamento a longo prazo, os bancos convencionais de germoplasma têm utilizado freezer na temperatura de 18 a $-20{ }^{\circ} \mathrm{C}$, contudo mesmo nessas temperaturas, o metabolismo das sementes ainda não é completamente interrompido.

Sementes de cumaru (Amburana cearensis (Allemao) A.C. Sm.) foram conservadas, com eficiência, nas embalagens saco de papel, saco de pano de algodão e papel alumínio, nos ambientes de laboratório $( \pm 25$ ${ }^{\circ} \mathrm{C}$ e $74,5 \%$ UR $)$ e geladeira $\left(6 \pm 2{ }^{\circ} \mathrm{C}\right.$ e $38 \% \pm 3$ UR $)$ por 90 dias e na embalagem de alumínio e ambiente de laboratório por 180 dias (Guedes et al., 2010). Sementes de Caesalpinia echinata Lam. quando armazenadas sob condições normais de ambiente $\left(22 \pm 7{ }^{\circ} \mathrm{C}\right)$ perderam a viabilidade em menos de três meses. No entanto, sob baixa temperatura (câmara fria a $7 \pm 1{ }^{\circ} \mathrm{C}$ ) foi possível manter a viabilidade das mesmas por até 18 meses, com germinação superior a $80 \%$ (Barbedo et al., 2002). O ambiente de laboratório, sem controle de temperatura e umidade relativa do ar, não foi eficiente para conservar a qualidade fisiológica das sementes de Acacia polyphylla DC. No entanto, a qualidade fisiológica foi mantida por dois anos, quando as sementes foram acondicionadas em embalagem impermeável e em câmara fria (Araújo Neto et al., 2005). Kissman et al. (2009), avaliando diferentes condições de armazenamento para Albizia hasslerii, (Chod.) Burkart, concluíram que as sementes desta espécie podem ser armazenadas por 90 dias em câmara fria, apresentando germinação superior a $50 \%$.

Devido à escassez de informações sobre o comportamento das sementes de catanduva durante o armazenamento, o presente trabalho teve por objetivo avaliar o desempenho das mesmas, armazenadas em diferentes embalagens e ambientes.

\section{MATERIAL E MÉTODOS}

As sementes foram colhidas em novembro de 2008, na Fazenda Experimental da Universidade Federal Rural do Semi-Árido (UFERSA), situada em Alagoinha, localizada a $20 \mathrm{~km}$ de Mossoró/RN. Antes de iniciar o experimento as sementes foram beneficiadas manualmente, retirando-se as chochas e danificadas por insetos.

Inicialmente, foi determinado o grau de umidade das sementes pelo método estufa a $105 \pm 3{ }^{\circ} \mathrm{C}$ por 24 horas conforme as Regras para Análise de Sementes - RAS (Brasil, 1992), utilizando-se duas sub-amostras de 10 gramas.

As sementes foram acondicionadas em frasco de vidro (volume $150 \mathrm{~mL}$ ), saco plástico e saco de papel contendo em cada recipiente, aproximadamente, 500 sementes. Todos os recipientes foram lacrados com fita adesiva, envoltos por saco preto para proteção contra luz e armazenados em ambiente controlado $\left(18-20{ }^{\circ} \mathrm{C}\right.$, $\pm 60 \%$ UR) e em ambiente (condições de laboratório nãocontroladas). Cada ambiente continha sete embalagens referentes aos diferentes tempos de armazenamento $(0$, $30,60,90,120,150,180$ e 210 dias).

Foram conduzidos, a cada 30 dias, dois ensaios 
simultaneamente, um no Laboratório de Análise de Sementes e outro em casa de vegetação, durante o período de dezembro de 2008 a julho de 2009. Em cada tempo de armazenamento foram conduzidos os seguintes testes:

Germinação (G): antes da semeadura, as sementes foram imersas em ácido sulfúrico concentrado por 15 minutos, de acordo com Benedito et al. (2008), para superar a dormência. Em seguida, oito repetições de 25 sementes foram dispostas em caixas tipo gerbox, contendo como substrato uma folha de papel mata-borrão umedecido com quantidade de água equivalente a 2,5 vezes o peso do papel sem hidratação (Brasil, 1992). As caixas foram transferidas para uma câmara de germinação regulada à temperatura constante de $30{ }^{\circ} \mathrm{C}$ com luz constante. A germinação final foi obtida pela relação número de plântulas germinadas/ número total de sementes x 100. A avaliação foi feita no décimo dia após a instalação do teste, quando foi observada estabilidade nos resultados obtidos, que foram expressos em porcentagem de plântulas normais de acordo com Brasil (1992).

Índice de velocidade de germinação (IVG): realizado simultaneamente com o teste de germinação, consistindo da avaliação diária das plântulas, à mesma hora, a partir do dia em que surgiram as primeiras plântulas normais. As avaliações foram feitas até o dia da última contagem (10 dias) e para cálculo do IVG foi utilizada a seguinte fórmula proposta por Maguire (1962):

$\mathrm{IVG}=\mathrm{G} 1 / \mathrm{N} 1+\mathrm{G} 2 / \mathrm{N} 2+\ldots+\mathrm{Gn} / \mathrm{Nn}$, onde:

$\mathrm{IVG}=$ Índice de velocidade de germinação

G1, G2, Gn = número de plântulas normais computadas na primeira, na segunda e na última contagem.

$\mathrm{N} 1, \mathrm{~N} 2, \mathrm{Nn}=$ número de dias de semeadura à primeira, segunda e última contagem.

Emergência de plântulas (EP): conduzido em casa de vegetação, utilizando-se quatro repetições de 50 sementes que foram semeadas em copos descartáveis (150 $\mathrm{mL}$ ), contendo como substrato areia lavada, previamente esterilizada em autoclave a $120^{\circ} \mathrm{C}$. Periodicamente, durante a avaliação da emergência, dependendo da necessidade foi feita irrigação a fim de manter o substrato sempre úmido. A emergência final foi calculada pela relação número de plântulas emergidas/número total de sementes x 100. A avaliação foi feita no vigésimo terceiro dia após a instalação do teste e os resultados expressos em porcentagem de plântulas normais.

O delineamento experimental utilizado foi $\mathrm{o}$ inteiramente casualizado, em esquema de parcela sub- subdividida, sendo alocados na parcela principal os ambientes de armazenamento (ambiente não-controlado e ambiente controlado) e nas sub-parcelas as embalagens (saco plástico, papel e frasco de vidro). As sub-subparcelas foram constituídas pelo tempo de armazenamento $0 ; 30$; $60 ; 90 ; 120 ; 150 ; 180$ e 210 dias. A análise de variância foi feita utilizando o programa ESTAT versão 2.0 (1992). Para a comparação entre as médias utilizou-se o teste de Tukey a $5 \%$ de probabilidade e, considerando quando houve efeito significativo do tempo de armazenamento ou interação entre este e outros fatores, fez-se um estudo de regressão, ajustando-se os modelos pelo programa Table Curve 2D (Jandel Scientific, 1991).

\section{RESULTADOS E DISCUSSÃO}

O grau de umidade inicial das sementes foi em torno de 9\% (Tabela 1). As sementes acondicionadas em saco de papel tiveram seu grau de umidade modificado de acordo com o ambiente de armazenamento. Em condições de laboratório, o grau de umidade das sementes chegou a $13,5 \%$ no final do experimento, enquanto que no ambiente controlado $\left(18-20{ }^{\circ} \mathrm{C}\right.$ e UR $\left.\pm 60 \%\right)$ o aumento do grau de umidade das sementes foi menor, atingindo $10,2 \%$ ao final do experimento. De acordo com Carvalho e Nakagawa (2000), mudanças na temperatura e umidade relativa provocam constantes ajustes no grau de umidade das sementes armazenadas em embalagem permeável ao vapor de água. $\mathrm{Na}$ embalagem de plástico, as sementes tiveram comportamento parecido com a embalagem de papel, ou seja, houve maior elevação do grau de umidade das sementes quando armazenadas em laboratório, atingindo $10,1 \%$ ao final do armazenamento, enquanto que em ambiente controlado, o grau de umidade das mesmas aos 210 dias foi de 9,8\%. Desse modo, o saco plástico ainda permitiu a entrada de vapor d'água, mesmo em menor quantidade. Os menores valores do grau de umidade das sementes foram obtidos na embalagem de vidro, em torno de 9,1\% para ambos os ambientes (Tabela 1). Silva (2007), armazenando sementes de cubiu (Solanum sessiliflorum) obteve resultados semelhantes ao deste trabalho, onde a embalagem impermeável manteve o grau de umidade das sementes constante. O conhecimento do grau de umidade das sementes é essencial para se determinar as condições adequadas para o armazenamento, que dependem da umidade relativa, a qual é influenciada pela temperatura do ambiente e pelo tipo de embalagem (Warhm, 1996). 
TABELA 1. Grau de umidade (\%) de sementes de catanduva (Piptadenia moniliformis Benth.) acondicionadas em diferentes embalagens e ambientes (ambiente não controlado - ANC e ambiente controlado - AC), durante 210 dias de armazenamento.

\begin{tabular}{ccccccccrr}
\hline \multirow{2}{*}{ Ambiente } & \multirow{8}{*}{ Embalagem } & \multicolumn{7}{c}{ Tempo de armazenamento (dias) } \\
\cline { 3 - 9 } & & 0 & 30 & 60 & 90 & 120 & 150 & 180 & 210 \\
\hline \multirow{3}{*}{ ANC } & Papel & 9,1 & 9,3 & 10,5 & 12,3 & 12,5 & 12,8 & 13,0 & 13,5 \\
& Plástico & 9,1 & 9,1 & 9,2 & 9,8 & 10,2 & 10,1 & 10,4 & 10,1 \\
& Vidro & 9,1 & 9,1 & 9,0 & 9,0 & 9,1 & 9,0 & 9,1 & 9,1 \\
\hline \multirow{3}{*}{ AC } & Papel & 9,1 & 9,2 & 9,9 & 10,3 & 10,5 & 10,8 & 10,4 & 10,2 \\
& Plástico & 9,1 & 9,1 & 9,1 & 9,7 & 9,7 & 9,6 & 9,7 & 9,8 \\
& Vidro & 9,1 & 9,1 & 9,0 & 9,0 & 9,1 & 9,0 & 9,0 & 9,0 \\
\hline
\end{tabular}

Para porcentagem de germinação verificou-se interação significativa entre o tempo de armazenamento e as embalagens. No início do armazenamento a germinação foi de $93 \%$. Observou-se redução da porcentagem de germinação das sementes de catanduva ao longo do tempo de armazenamento. Porém, constatou-se que nas sementes acondicionadas em frasco de vidro, o declínio na germinação foi menos acentuado do que naquelas que estavam armazenadas em saco plástico e papel (Figura 1). $\mathrm{Na}$ Tabela 2, observa-se que até 60 dias de armazenamento não houve diferença significativa entre os três tipos de embalagens; aos 90 dias de armazenamento verificou-se menor germinação para as sementes acondicionadas em papel em relação àquelas embaladas em plástico e vidro, comportamento estemantidoaté 150 dias de armazenamento. A partir de 180 dias, os valores de germinação obtidos para as sementes em embalagem de vidro foram estatisticamente superiores às demais. Varela e Barbosa (1987), estudando diferentes ambientes e embalagens na conservação de sementes de cedrorana (Cedrelinga catenaeformis), observaram que a partir de 30 dias, as sementes que foram acondicionadas em sacos de papel apresentaram redução no poder germinativo. Para o armazenamento de sementes de Cedrela fissilis Vell., por doze meses, com grau de umidade de 10\%, Corvello et al., (1999) recomendaram que as mesmas fossem acondicionadas em embalagem de vidro transparente fechado hermeticamente e mantidas em câmara fria. Resultados contrários foram encontrados por Maeda e Mathes (1984), investigando a viabilidade das sementes de Tabebuia chrysotricha, T. avellanedae, T. impetiginosa, $T$. rosea e $T$. heptaphylla, os autores encontraram diferentes índices de germinação e viabilidade nesse gênero, quando armazenadas em vidros hermeticamente fechados ou em sacos de papel, ressaltando-se que as sementes armazenadas em vidros, à temperatura de $30{ }^{\circ} \mathrm{C}$ apresentaram menor longevidade.

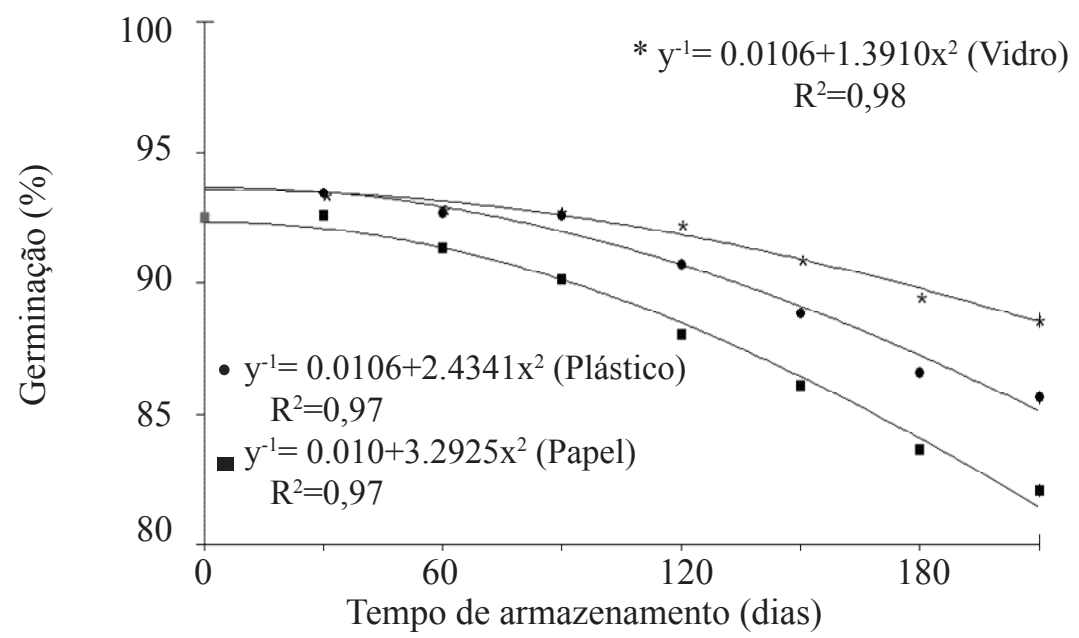

FIGURA 1. Porcentagem de germinação de sementes de catanduva (Piptadenia moniliformis Benth.) armazenadas em diferentes condições e embalagens durante 210 dias de armazenamento. 
TABELA 2. Porcentagem de germinação de sementes de catanduva (Piptadenia moniliformis Benth.) armazenadas em diferentes condições ambientais e embalagens durante 210 dias de armazenamento.

\begin{tabular}{lcccccccc}
\hline \multirow{2}{*}{ Embalagens } & \multicolumn{7}{c}{ Tempo de armazenamento (dias) } \\
\cline { 2 - 9 } & 0 & 30 & 60 & 90 & 120 & 150 & 180 & 210 \\
\hline Plástico & $93,0 \mathrm{a}$ & $93,43 \mathrm{a}$ & $92,68 \mathrm{a}$ & $92,56 \mathrm{a}$ & $90,68 \mathrm{a}$ & $88,81 \mathrm{a}$ & $86,06 \mathrm{~b}$ & $85,62 \mathrm{~b}$ \\
Papel & $93,0 \mathrm{a}$ & $92,81 \mathrm{a}$ & $91,93 \mathrm{a}$ & $90,12 \mathrm{~b}$ & $88,0 \mathrm{~b}$ & $86,06 \mathrm{~b}$ & $83,68 \mathrm{~b}$ & $82,06 \mathrm{c}$ \\
Vidro & $93,0 \mathrm{a}$ & $93,37 \mathrm{a}$ & $92,81 \mathrm{a}$ & $92,75 \mathrm{a}$ & $92,25 \mathrm{a}$ & $90,93 \mathrm{a}$ & $89,43 \mathrm{a}$ & $88,56 \mathrm{a}$ \\
\hline
\end{tabular}

Médias seguidas da mesma letra minúscula na coluna não diferem entre si pelo teste de Tukey em $5 \%$ de probabilidade.

Desdobrando-se o tempo de armazenamento dentro de cada tipo de embalagem, observou-se que não houve redução significativa na germinação até 150 dias quando se utilizou a embalagem de vidro e até os 120 dias e 90 dias, respectivamente quando se utilizou saco plástico e papel. Dessa forma, sementes acondicionadas em frasco de vidro tiveram a germinação inicial preservada por maior período de tempo (Figura 1). Resultados divergentes foram obtidos por Matos et. al. (2008), que não obtiveram sucesso quando utilizaram a embalagem de vidro para armazenar sementes de pau-de-jangada (Apeiba tibourbou), onde o poder germinativo das sementes, armazenadas em ambiente natural, decresceu gradativamente alcançando $46 \%$ aos 225 dias de armazenamento.

Também foi observada interação significativa entre o tempo de armazenamento e as embalagens para o índice de velocidade de germinação. $\mathrm{O}$ valor inicial para o IVG foi de 11,6. Desdobrando-se a embalagem dentro de cada tempo de armazenamento observou-se que a partir de 60 dias de armazenamento foi possível detectar diferenças significativas entre as embalagens, onde a embalagem de vidro foi estatisticamente superior às demais, como pode ser observado pelo maior IVG ao final do experimento. Entre 60 e 120 dias de armazenamento não houve diferença significativa entre o IVG das sementes acondicionadas em saco de papel e de plástico. Já a partir de 150 dias, foi possível detectar diferença significativa entre as três embalagens testadas, observando-se menor IVG para as sementes mantidas em saco de papel e maior para sementes acondicionadas em vidro (Tabela 3). Santos e Paula (2007), avaliando o IVG de sementes Sebastiania commersoniana, armazenadas em diferentes embalagens, ambientes e períodos de armazenamento, verificaram que a embalagem de vidro proporcionou melhor resultado do que a embalagem de plástico a partir de 389 dias após o armazenamento.

TABELA 3. Índice de velocidade de germinação de sementes de catanduva (Piptadenia moniliformis Benth.) armazenadas em diferentes condições ambientais e embalagens durante $\mathbf{2 1 0}$ dias de armazenamento.

\begin{tabular}{lcccccccc}
\hline \multirow{2}{*}{ Embalagens } & \multicolumn{7}{c}{ Tempo de armazenamento (dias) } \\
\cline { 2 - 9 } & 0 & 30 & 60 & 90 & 120 & 150 & 180 & 210 \\
\hline Plástico & $11,59 \mathrm{a}$ & $11,13 \mathrm{a}$ & $10,31 \mathrm{~b}$ & $9,88 \mathrm{~b}$ & $9,51 \mathrm{~b}$ & $9,38 \mathrm{~b}$ & $9,11 \mathrm{~b}$ & $9,08 \mathrm{~b}$ \\
Papel & $11,59 \mathrm{a}$ & $10,94 \mathrm{a}$ & $10,23 \mathrm{~b}$ & $9,79 \mathrm{~b}$ & $9,04 \mathrm{~b}$ & $8,73 \mathrm{c}$ & $8,29 \mathrm{c}$ & $8,33 \mathrm{c}$ \\
Vidro & $11,59 \mathrm{a}$ & $11,44 \mathrm{a}$ & $11,15 \mathrm{a}$ & $10,63 \mathrm{a}$ & $10,46 \mathrm{a}$ & $10,22 \mathrm{a}$ & $9,82 \mathrm{a}$ & $9,78 \mathrm{a}$ \\
\hline
\end{tabular}

Médias seguidas da mesma letra minúscula na coluna não diferem entre si pelo teste de Tukey em $5 \%$ de probabilidade

Pela Figura 2, observa-se que houve redução do IVG com o decorrer do armazenaemento quando se utilizou a embalagem de papel, o que também ocorreu para a embalagem de plástico, embora neste caso, a redução tenha sido mais acentuada até 120 dias de armazenamento. Quando se utilizou a embalagem de vidro a redução do 
IVG foi bem menos acentuada que nas embalagens de plástico e papel declinando ligeiramente até os 210 dias. Perez et al., (1999), armazenando sementes de canafístula acondicionadas em embalagens de vidro, mantidas em temperatura ambiente de laboratório, perceberam a redução do vigor após 90 dias de armazenamento. De acordo com Vieira e Carvalho (1994), a deterioração da semente evidencia-se, primeiramente, pela redução da velocidade de germinação. Resultados obtidos por Piña-
Rodrigues e Jesus (1992), mostraram que em condições de laboratório, a viabilidade de sementes de cedrorosa (Cedrela angustifolia S. ET. MOC) foi mantida por apenas 75 dias, em embalagem permeável (saco de papel). Já quando as sementes foram armazenadas em câmara fria, possibilitou a conservação da viabilidade por um período de três anos, embora com valores inferiores (23\%) à germinação inicial (71\%), independente do tipo de embalagem utilizada.

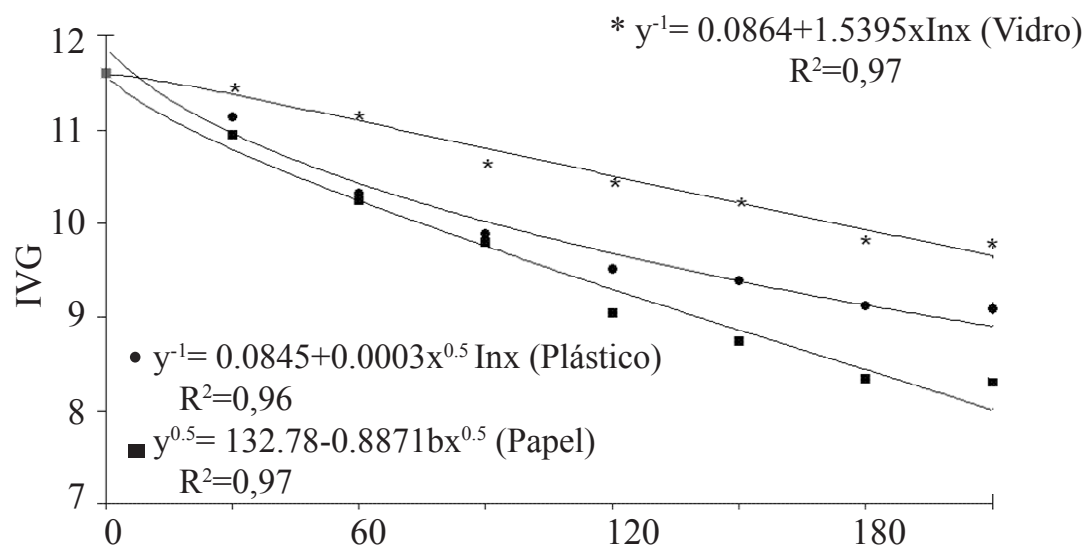

Tempo de armazenamento (dias)

FIGURA 2. Índice de velocidade de germinação de sementes de catanduva (Piptadenia moniliformis Benth.) armazenadas em diferentes condições ambientais e embalagens, durante 210 dias de armazenamento.

Não foi observada interação significativa entre os fatores para emergência de plântulas, porém houve efeito isolado dos fatores. $\mathrm{O}$ valor inicial da emergência de plântulas foi de $91 \%$, sendo que o ambiente controlado proporcionou melhor conservação das sementes do que o ambiente de laboratório (Tabela 4). O ambiente de laboratório, sem controle de temperatura e umidade relativa do ar não foi eficiente para manutenção da viabilidade das sementes de Acacia polyphyilla DC, as quais tiveram a sua germinação reduzida a partir do quarto mês de armazenamento (Araújo Neto et al., 2005). Avaliando diferentes ambientes de armazenamento de sementes de Albizia hassleri, Kissmann (2009) observou que as plântulas provenientes de sementes armazenadas em câmara fria foram mais vigorosas. Esses resultados diferem em parte com os encontrados por Matos et al., (2008), onde condição mais adequada para conservação das sementes de pau-de-jangada, com menor perda de viabilidade e vigor, foi o ambiente natural de laboratório, utilizando-se tanto a embalagem saco de papel Kraft como o saco de polietileno. Sementes de Caesalpinia echinata Lam., quando armazenadas sob condições normais de ambiente $\left(22 \pm 7{ }^{\circ} \mathrm{C}\right)$, perderam a viabilidade em menos de três meses, enquanto sob temperatura baixa (câmara fria a $7 \pm 1{ }^{\circ} \mathrm{C}$ ) foi possível manter a viabilidade das mesmas por até 18 meses, com germinação superior a $80 \%$ (Barbedo et al., 2002).

\section{TABELA 4. Emergência de plântulas de catanduva (Piptadenia moniliformis armazenadas em diferentes ambientais.}

\begin{tabular}{lc}
\hline Condições ambientais & Emergência de plântulas (\%) \\
\hline Ambiente não controlado & $84,83 \mathrm{~b}$ \\
Ambiente controlado & $86,36 \mathrm{a}$ \\
\hline
\end{tabular}

Médias seguidas de letras distintas diferem entre si pelo teste de Tukey em $5 \%$ de probabilidade 
Com relação às embalagens estudadas, os maiores valores de emergência de plântulas de catanduva foram obtidos quando foram utilizadas as embalagens vidro e saco plástico (Tabela 5). Houve redução na emergência do longo do tempo do período de armazenamento (Figura 3). Resultados semelhantes foram encontrados por Silva (2008), em sementes de mulungu (Erytrina velutina Wild)), onde houve diminuição da emergência ao longo do armazenamento, porém as sementes armazenadas em embalagem de vidro tiveram queda menos acentuada no vigor do que aquelas acondicionadas em embalagem de pano e papel. Guedes et al. (2010) verificaram que houve redução acentuada na emergência de plântulas de $A$. cearensis, cujas sementes foram acondicionadas em saco de papel e mantidas em ambiente de laboratório. Souza. (2005) não recomendam a utilização de embalagens de papel para sementes de Tabebuia serratifolia (Vahl.) Nich., pois nesta embalagem houve redução significativa do vigor ao longo do armazenamento.

\section{TABELA 5. Emergência de plântulas de catanduva (Piptadenia moniliformis Benth.) armazenadas em diferentes embalagens.}

\begin{tabular}{lc}
\hline Embalagens & Emergência de plântulas (\%) \\
\hline Plástico & $86,68 \mathrm{a}$ \\
Papel & $82,76 \mathrm{~b}$ \\
Vidro & $87,76 \mathrm{a}$ \\
\hline
\end{tabular}

Médias seguidas de letras distintas diferem entre si pelo teste de Tukey em $5 \%$ de probabilidade.

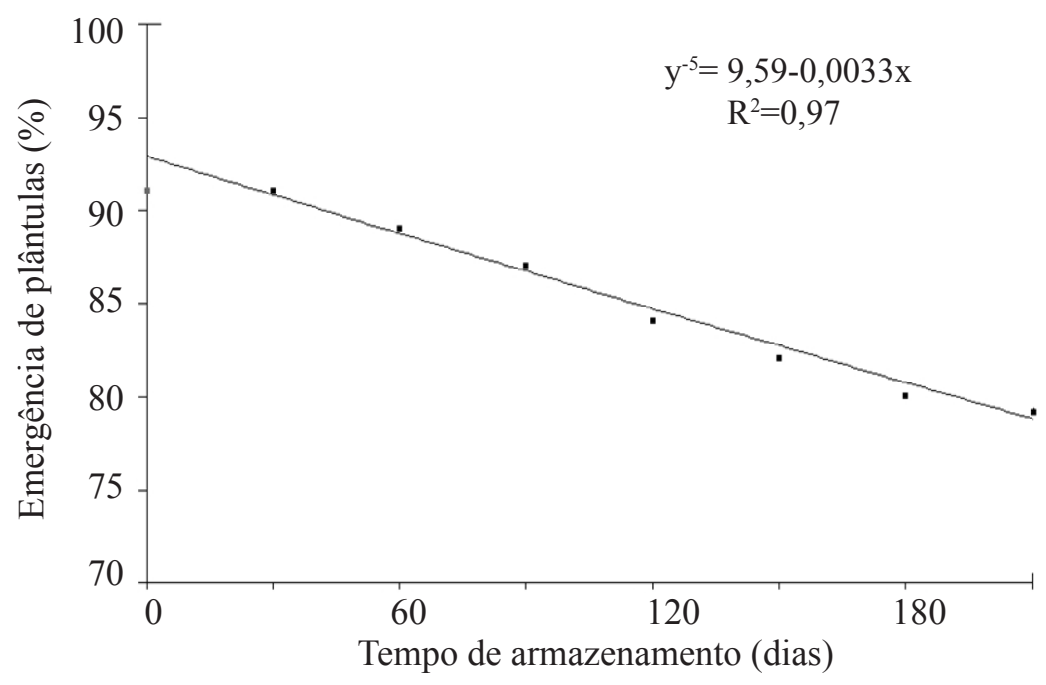

FIGURA 3. Emergência de plântulas de catanduva (Piptadenia moniliformis Benth.) armazenadas em diferentes condições ambientais e embalagens, durante 210 dias de armazenamento.

\section{CONCLUSÃO}

As sementes de catanduva podem ser acondicionadas tanto em embalagem de vidro quanto em saco plástico por 210 dias, sendo o ambiente controlado $\left(18-20^{\circ} \mathrm{C}, \pm 60 \%\right.$ UR) o mais adequado.

\section{REFERÊNCIAS}

ARAÚJO NETO, J.C.; AGUIAR, I.V.; FERREIRA, V.M.; RODRIGUES, T.J.D. Armazenamento e requerimento fotoblástico de sementes de Acacia polyphylla DC. Revista Brasileira de Sementes, v.27, n.1, p.115-124, 2005.

AZÊREDO, G.A. Qualidade fisiológica de sementes de Piptadenia moniliformis Benth. 2009.121f. Tese (Doutorado em Agronomia - Produção Vegetal) Universidade Estadual Paulista, Faculdade de Ciências Agrárias e Veterinárias, São Paulo, 2009.

BARBEDO, C.J.; BILIA, D.A.C.; FIGUEIREDO, R.R.CL. Tolerância à dessecação e armazenamento de sementes de Caesalpinia echinata Lam (pau-brasil), espécie da Mata Atlântica. Revista Brasileira de Botânica, v.25, n.4, 
p.431-439, 2002.

BENEDITO, C.P.; TORRES, S.B.; RIBEIRO, M.C.C.; NUNES, T.A. Superação da dormência de sementes de catanduva (Piptadenia moniliformis Benth.). Revista Ciência Agronômica, v.39, n.1, p.90-93, 2008.

BRASIL. Ministério da Agricultura e Reforma Agrária. Secretaria Nacional de Defesa Agropecuária. Departamento Nacional de Produção Vegetal. Coordenação de Laboratório Vegetal. Regras para Análise de Sementes. Brasília, DF, 1992. 365p.

CARVALHO, N.M.; NAKAGAWA, J. Sementes: ciência, tecnologia e produção. 4.ed. Jaboticabal: FUNEP, 2000. $588 \mathrm{p}$.

CARVALHO, L.R.; SILVA, E.A.A.; DAVIDE, A.C. Classificação de sementes florestais quanto ao comportamento no armazenamento. Revista Brasileira de Sementes, v.28, n.2, p.15-25, 2006.

CARNEIRO, J.G.A.; AGUIAR, I.B. Armazenamento de sementes. In: AGUIAR, I.B.; PIÑA-RODRIGUES, F.C.M.; FIGLIOLIA, M.B. Sementes florestais tropicais. Brasília, DF: ABRATES, 1993. p.333-350.

CORVELLO, W.B.V.; VILLELA, F.A.; NEDEL, J.L.; PESKE, S.T. Época de colheita e armazenamento de sementes de cedro (Cedrela fissilis Vell.). Revista Brasileira de Sementes, v.21, n.2, p.28-34, 1999.

DAVIDE, A.C.; CARVALHO, L.R.; CARVALHO, M.L.M.; GUIMARÃES, R.M. Classificação fisiológica de sementes de espécies florestais pertencentes à família Lauraceae quanto à capacidade de armazenamento. Revista Cerne, v.9, n.1, p.29-35, 2003.

ESTAT 2.0. Sistema de análise estatística. Jaboticabal: Pólo Computacional - Departamento de Ciências Exatas UNESP, 1992.

FOWLER, J.A.P. Superação de dormência e armazenamento de sementes de espécies florestais. In: GALVÃO, A. P. $M$. Reflorestamento de propriedades rurais para fins produtivos e ambientais. Brasília, DF, Embrapa, 2000. $351 \mathrm{p}$.

FLORIANO, E.P.Armazenamentodesementes florestais. Santa Rosa: ANORGS, 2004. 10p. (Caderno didático).

GUEDES, R.S.; ALVES, E.U.; GONÇALVES, E.P.; VIANA, J.S.; FRANÇA, P.R.C.; SANTOS, S. S. Qualidade fisiológica de sementes armazenadas de Amburana cearensis (Allemao) A.C. Smith. Semina: Ciências Agrárias, v.31, n. 2, p.331-342, abr./jun. 2010.
JANDEL SCIENTIFIC. Table curve: curve fitting software. Corte Madera, CA: Jandel Scientific. 1991, 280p.

KISSMANN, C.; SCALON, S.P.Q.; MUSSURY, R.M; RABAINA, A.D. Germinação e armazenamento de sementes de Albizia hassleri. Revista Brasileira de Sementes, v.31, n.2, p.104-115. 2009.

LORENZI, H. Árvores brasileiras: manual de identificação e cultivo de plantas arbóreas do Brasil. São Paulo: Nova Odessa, 2002. 384p.

MAEDA, J.A.; MATHES, L.A.F. Conservação de Sementes de Ipê. Bragantia, v.43, n.1, p.51-61, 1984.

MAGUIRE, J.D. Speed of germination-aid in selection and evaluation for seedlig emergence and vigor. Crop Science, v.2, n..1, p.176-177, 1962.

MATOS, V.P.; FERREIRA, E.G.B. de S.; FERREIRA, R.L.C.; SENA, L.H. de M.; SALES, A.G. de F.A. Efeito do tipo de embalagem e do ambiente de armazenamento sobre a germinação e o vigor das sementes de Apeiba tibourbou AUBL. Revista Árvore, v.32, n.4, p.617-625, 2008.

NODARI, R.O.; FANTINI, A.C.; GUERRA, M.P.; REIS, M.S.; SCHUCH, O. Conservação de frutos e sementes de palmiteiro (Euterpe edulis Matius) sob diferentes condições de armazenamento. Revista Árvore, v.22, n.1, p.1-10, 1998.

PEREZ, S.C.J.G.A.; FANTI, S.C. CASALI, C.A. Influência do armazenamento, substrato, envelhecimento precoce e profundidade de semeadura na germinação de canafístula. Bragantia, v.58, n.1, p.57-68, 1999.

PIÑA-RODRIGUES, F.C.M.; JESUS, R.M. de.Comportamento de sementes de cedro-rosa (Cedrela angustifolia S. ET. MOC) durante o armazenamento. Revista Brasileira de Sementes, v.14, n.1, p.31-36, 1992.

RÊGO, G.M.; POSSAMAI, E. Jacarandá-da-Bahia (Dalbergia nigra Vellozo) Leguminoseae - Papilionoideae: produção de mudas. Colombo: Embrapa Florestas, 2003. p.1-3. (Comunicado Técnico, 106).

SANTOS, I.R.I. Criopreservação: potencial e perspectivas para a conservação de germoplasma vegetal. Revista Brasileira de Fisiologia Vegetal, v.12 p.70-84, 2000.

SANTOS, S.R.G.; AGUIAR, I.B. Germinação de sementes de branquilho (Sebastiania commersoniana (Bill.) Smith \& Downs) em função do substrato e do regime de temperatura. Revista Brasileira de Sementes, v.22, n.1, p.120-126, 2000.

SANTOS, S.R.G.; PAULA, R.C. Qualidade fisiológica de 
sementes de Sebastiania commersoniana (Bill.) Smith \& Downs) durante o armazenamento. Scientia Florestalis, n.74, p.87-94, 2007.

SILVA, D.P. Armazenamento de sementes de cubiu (Solanum sessiliflorum): influência da embalagem, do grau de umidade e da temperatura. 2007. 38f. Dissertação (Mestrado em Ciências Agrárias) - Universidade Federal do Amazonas, Manaus-AM, 2007.

\section{SILVA, K.B. Tecnologia de sementes de Erytrina velutina} Willd. 2008, 138f. Dissertação (Mestrado em Tecnologia de sementes) - Universidade Federal da Paraíba, Areia-PB, 2008.
SOUZA, V.C.; BRUNO, R.L.A. ANDRADE, L.A. Vigor de sementes armazenadas de ipê-amarelo Tabebuia serratifolia (Vahl.) Nich. Revista Árvore,v.29, n.6, p.833-841, 2005.

VARELA, V.P.; BARBOSA, A.P. Conservação de sementes de cedrorana (Cedrelinga catenaeformis Ducke). Acta Amazônica, v.16/17, n.1, p.549-556. 1987.

VIEIRA, R.D.; CARVALHO, N.M. Testes de vigor em sementes. Jaboticabal: FUNEP, 1994. 164p.

WARHM, E.J.A. Comparison of packing materials for seed with particular reference to humid environments. Seed Science and Technology, v.14, n.1, p.191-211, 1996. 